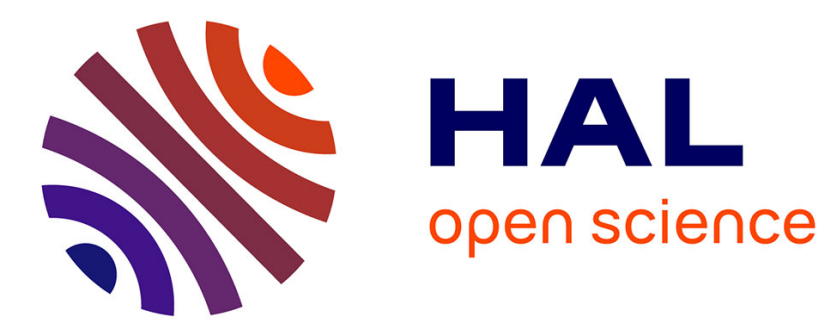

\title{
Investigation of the relationships between anatomical pattern, density and local swelling of oak wood
}

\author{
Eric Badel, R Bakour, Patrick Perre
}

\section{To cite this version:}

Eric Badel, R Bakour, Patrick Perre. Investigation of the relationships between anatomical pattern, density and local swelling of oak wood. IAWA Journal, 2006, 27 (1), pp.55-71. hal-01189276

\section{HAL Id: hal-01189276 \\ https://hal.science/hal-01189276}

Submitted on 18 Feb 2019

HAL is a multi-disciplinary open access archive for the deposit and dissemination of scientific research documents, whether they are published or not. The documents may come from teaching and research institutions in France or abroad, or from public or private research centers.
L'archive ouverte pluridisciplinaire HAL, est destinée au dépôt et à la diffusion de documents scientifiques de niveau recherche, publiés ou non, émanant des établissements d'enseignement et de recherche français ou étrangers, des laboratoires publics ou privés. 


\title{
INVESTIGATION OF THE RELATIONSHIPS BETWEEN ANATOMICAL PATTERN, DENSITY AND LOCAL SWELLING OF OAK WOOD
}

\author{
E. Badel, R. Bakour and P. Perré \\ LERMAB, UMR 1093 INRA/ENGREF, Université Henri Poincaré, 14 rue Girardet, \\ F-54042 Nancy, France [E-mail: badel@engref.fr or perre@engref.fr]
}

\begin{abstract}
SUMMARY
We coupled a digital X-ray imaging system with a humid air conditioner. This new configuration allows the shrinkage behaviour of thin samples to be measured. In order to control both the temperature and the relative humidity in the chamber, an air generator was developed which ensures very stable conditions even over several months. The X-ray beam passes through the chamber to the $2 \mathrm{D}$ detector. Twelve samples can be placed on a rotating sample holder. The strain field due to the moisture content variations is determined by an image correlation algorithm, which compares X-ray images collected at different moisture conditions. Moreover, inspection by X-ray simultaneously produces complementary data: the local density and the spatial organisation of the tissues within the anatomical pattern. Twelve oak samples, chosen for their wide variability of the anatomical pattern, were characterised using this device.

Some models available in the literature are used to predict the swelling. The comparison between measurements and prediction is rather poor. The variable anatomical structure of the annual rings permits some explanations for this decrepancy and leads to the conclusion that the complete spatial organisation of the tissues has to be quantified to understand and to predict the behaviour of oak wood.
\end{abstract}

Key words: Anatomy, oak, shrinkage, imaging, X-ray, microscopy, structure-property relations.

\section{INTRODUCTION}

Shrinkage is one of the most important concerns when using wood as a material. Indeed, wood is a highly hygroscopic material, which can absorb or release water to reach an equilibrium depending on the ambient conditions. Moisture content variations can produce important deformations (shrinkage or swelling) or checks in structural elements. In addition, because the shrinkage value depends strongly on the species, the genetic effect, the growth conditions and the position within the tree, its prediction by macroscopic characters such as density, age and annual ring width remains usually very poor.

This means that the understanding of shrinkage behaviour lies in the internal structure of wood. This approach needs different scales to be considered. For example, the 
variation of anisotropy between the longitudinal and the transverse direction is known to be closely dependent on the microfibril angle in the different cell wall layers. Many experiments have been carried out to measure this anisotropy ratio (Harris \& Meylan 1965). Other experimental devices were developed to determine the microfibril angle. These mainly use X-ray technologies like diffraction (Lichtenegger et al. 1999; Evans \& Ilic 2001) or observation techniques under an optical microscope.

At the same time, several modelling approaches have been proposed to establish deterministic links between some structural parameters (structure of the cell wall layers, thickness of the layers, etc.) and the longitudinal/transverse anisotropy (Persson 2000; Yamamoto et al. 2001).

On the other hand, several studies have tried to explain the transverse anisotropy (radial/tangential anisotropy). At the level of cell groups, no broad consensus emerges from the literature. The main parameters, which are mentioned to explain the transverse anisotropy, are the cell organisation, aligned or staggered rows or the difference of properties between radial and tangential cell walls. Recent results obtained in our laboratory suggest that the cumulative effects of the cellular shape and the local anisotropy of the cell walls is responsible for transverse anisotropy (Perré 2002).

At the level of the entire annual ring, different factors (the alternation of earlywood and latewood, the presence and the size of ray cells, the partition of different tissues, etc.) can explain the great range of experimental values that can be measured (Kawamura 1979; El Amri 1987).

Due to its economical importance, oak is among the most studied hardwood species in west and central Europe. Its structure is very heterogeneous and can offer a great variability, visible at the annual ring level to the naked eye, depending on its genetic origin or growth conditions (Fig. 1).

We developed a chain of modelling tools capable of predicting the elastic and shrinkage properties of oak wood from the morphology of its annual ring (Badel \& Perré 2002) This work is based on a cognitive approach and uses homogenisation techniques to pass from a microscopic scale where data should be experimentally available to a macroscopic scale were properties are predicted. Assuming that the annual ring is a composite material, the knowledge of the individual properties of the components and the
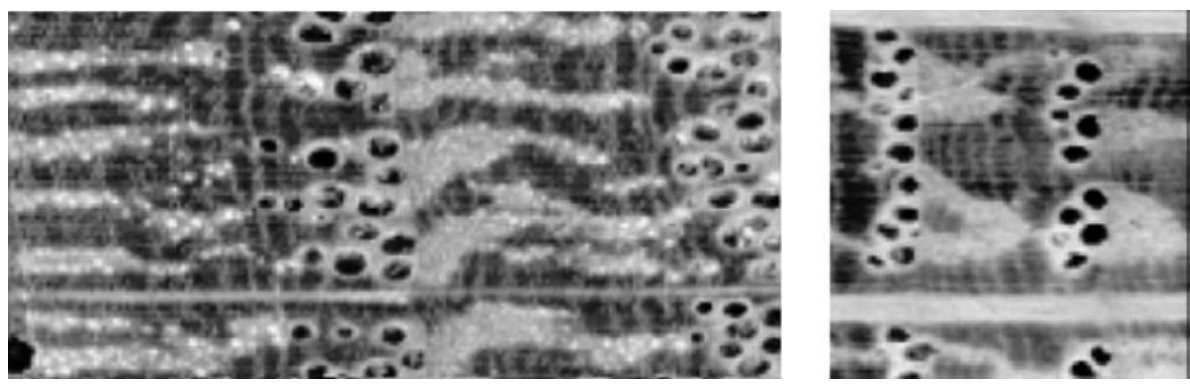

Fig. 1. Two different anatomical patterns of oak. The number of vessels, annual ring width, shape of the fibre zones: the genetic origin and the growth conditions lead to such variable structures. 
information about their spatial distribution over the representative elementary volume (R.E.V.) allow the properties of the composite to be computed.

Several experimental devices have been developed in the laboratory in order to measure properties of micro-samples made of one single tissue: fibre zone, ray cells, parenchyma zone in the transverse plane:

- the Young modulus and the Poisson's ratio are measured by tensile tests under an optical microscope (Badel \& Perré 1999; Farruggia \& Perré 2000),

- shrinkage values are determined from digital X-ray images of micro-samples gathered at different levels of moisture content (Badel \& Perré 2001).

To complete these experimental characterisation studies, several specific software applications, most of them developed in the laboratory, allow the macroscopic properties to be predicted from the real tissue morphology of wood samples (Perré 2002; Perré $\&$ Badel 2003). The representation step consists in building a Finite Element Mesh directly from X-ray views of some annual rings of oak samples. The homogenisation step consists of computing the macroscopic properties from the morphology of the R.E.V. and the microscopic properties of each phase. The standalone software MorphoPore is used for that purpose.

For the sake of argument, let us explain this principle for shrinkage. Indeed, the macroscopic shrinkage value is not a simple 'average' of the different microscopic shrinkage values of each phase. The influence of each tissue on the global properties is weighted by its mechanical properties that have to be taken into account in the calculation. For each isolated tissue 'free' shrinkage occurs when it can move without stress. 'Constrained shrinkage' occurs when the different components are linked together. In this case, the displacement of each phase should be compatible with the displacement of its neighbours at the interface. The homogenisation procedure proposes a rigorous framework to account for these facts.

This study presents the coupling of a X-ray imaging system and an air conditioner. This original configuration has been developed to validate our modelling approach. It allows both shrinkage values at the level of annual rings and the tissue morphology to be determined on several samples at the same time.

\section{MATERIAL AND METHODS}

\section{A versatile X-ray imaging device}

Several techniques have been developed to follow the dimensional changes of a sample during shrinkage. On small samples, non-contact strain measurements are required to ensure a free shrinkage. Optical methods (with a camera or a microscope) allow the surface of a sample to be measured, hence the shrinkage coefficients to be determined in two directions simultaneously (Boutelje 1962; Mariaux 1989). Laser beams permit the shadow of a sample to be measured with high accuracy in 1-D (Botosso 1997) or in 2-D using a dual-head device (May \& Perré 2002). A typical resolution of $0.05 \mu \mathrm{m}$ and a repeatability of $0.3 \mu \mathrm{m}$ are obtained with such equipment, which means that the accuracy in shrinkage measurement is better than $0.01 \%$ for $10 \mathrm{~mm}$ wide samples. 


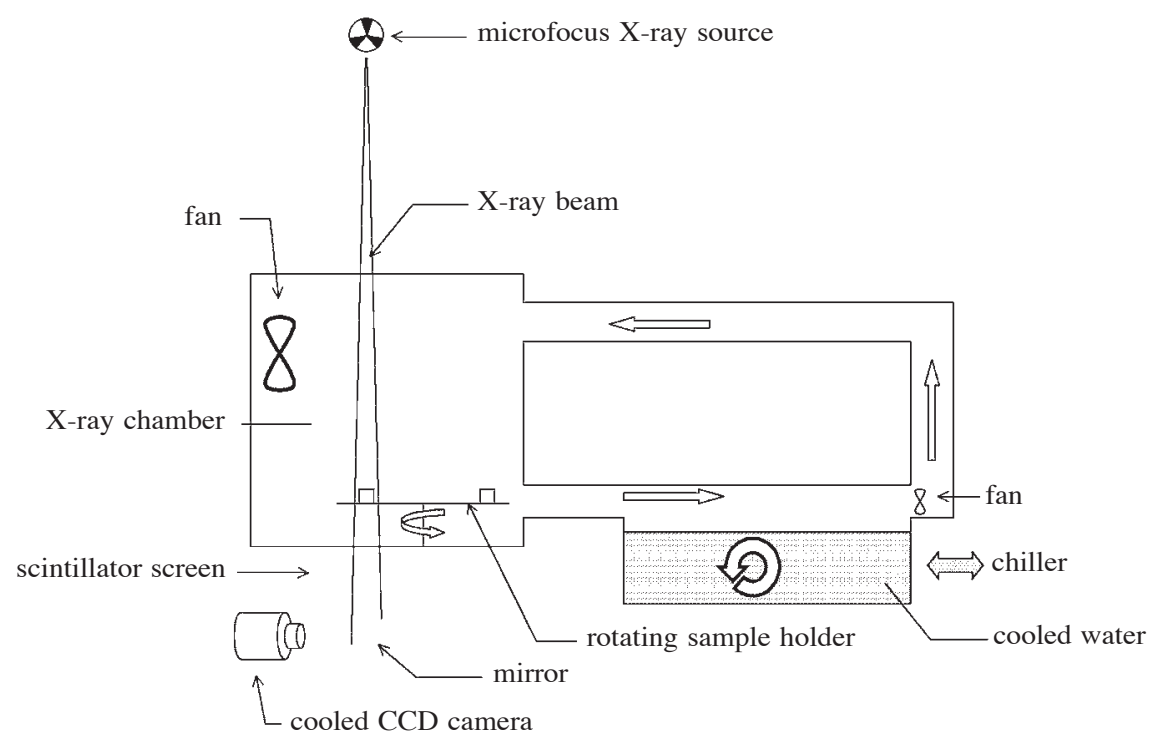

Fig. 2. Schematic diagram of the complete device. The relative humidity of the X-ray chamber is determined by the temperature of the air flux and the water temperature set at the dew point. A platinum sensor placed in the chamber measures the dry temperature.

The method chosen in this study uses the principle of X-ray attenuation. Thanks to the recent advances in the field of X-ray detection, especially in digital detection, this technique is well adapted to follow physical phenomena (Rondot et al. 1994). The method measures the attenuation of a polychromatic X-ray beam by the wood sample. Because the principle is based on the direct projection of the sample shade, a microfocus $\mathrm{X}$-ray generator is required to ensure a good spatial resolution (around $10 \mu \mathrm{m}$ for our application). The residual beam is projected onto a 2-D scintillator. The latter converts $\mathrm{X}$-ray photons into visible light. This low-light signal is detected by a cooled CCD camera (Fig. 2). The technical specifications of the different elements of this imaging system are detailed in Badel \& Perré (2001).

The design of the device is intentionally flexible. Assuming that the spatial resolution of the detector is fixed, the real spatial resolution of the sample is a direct function of the X-ray magnification, i.e. the source-sample distance over the source-detector distance. Note, however, that the size of the source spot is the theoretical limitation for the spatial resolution. The position of all components can be modified. This feature allows any possible compromise between the size of the sample and the spatial resolution to be chosen.

Finally, assuming that the signal/noise ratio increases with the total number of detected photons, the exposure time determines the quantitative quality of the image. Each pixel of the image represents the local attenuation property of the sample. Assumed that $I_{0}$ is the incident beam (before the sample) and $I$ is the transmitted beam (after the sample), the grey level of each pixel is equal to the $I / I_{0}$ ratio. 


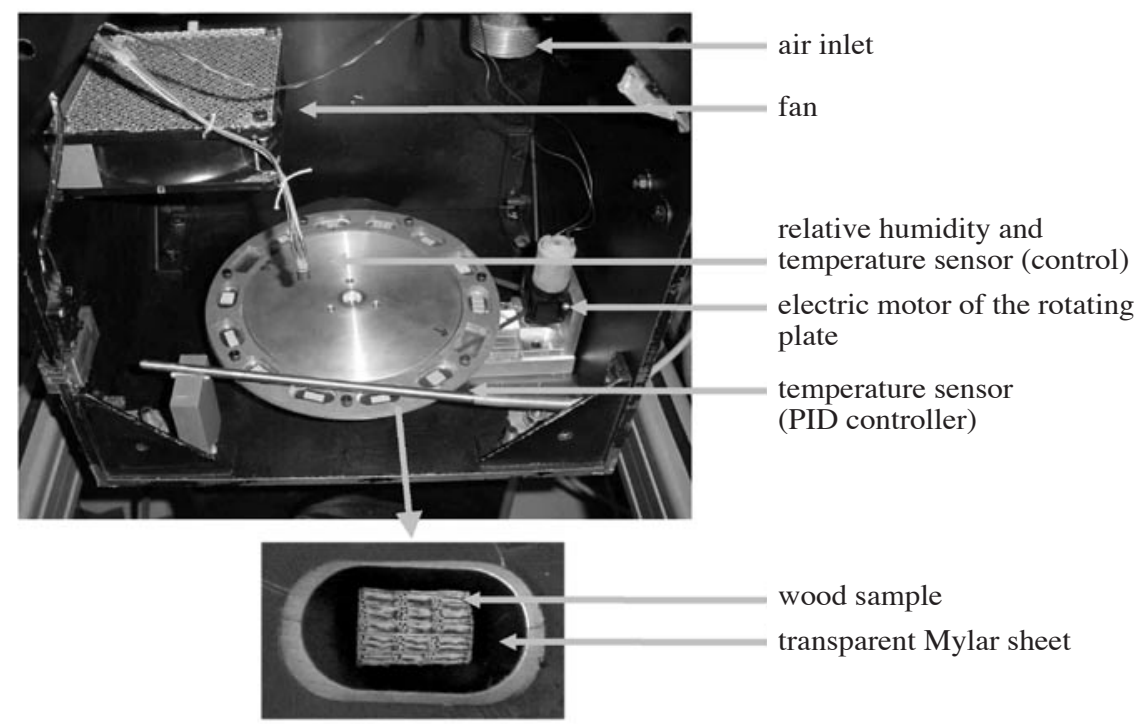

Fig. 3. The 'sample box'. The temperature sensor is linked to a PID controller that drives the air generator. Another sensor records the real relative humidity and temperature in the box. The electric motor allows any sample to be placed in the X-ray beam. The samples are placed on a thin Mylar film.

The central box, where the sample is installed, is designed to receive further equipment. In the present study, a specific rotating sample holder has been built. It consists of a metallic plate with 14 windows covered by a thin Mylar sheet $100 \mu \mathrm{m}$ thick almost transparent to the X-ray beam. From these windows, two are kept free to gather the reference incident beam $I_{0}$, which means that 12 samples can be installed simultaneously on the disk (Fig. 3). A small motor ensures the rotation of the disk, so that any sample can be submitted to the X-ray beam without opening the closed chamber, hence without perturbation of the air condition.

\section{Control of temperature and relative humidity}

\section{The air conditioner}

In order to gather images of a sample at different moisture content values, the temperature and the relative humidity of the surrounding air should be controlled. At first, the 'sample box' has to be airtight: a thin Mylar sheet insulates the windows used by the $\mathrm{X}$-ray beam to enter and exit. Then, two lateral ducts allow controlled air to circulate to and from the chamber.

The principle of the air conditioner is as follows: a ventilator forces a strong air flow above a water container. The temperature of this water is accurately controlled at the dew point temperature using a water cooler. The circulation of the water in the container ensures a very good homogeneity of the water temperature. In order to maximise the exchange, the air flow and the water flow are opposite. The temperature Platinum sensor (Pt 100) is placed near the samples. A Proportional, Integral and Derivative (P.I.D.) 
controller drives an electric resistance to adjust the air temperature at the set point within $\pm 0.1^{\circ} \mathrm{C}$. Only one part of the main air flow is by-passing in the X-ray chamber through the two ducts. Because the air flow is rather weak, a small fan is placed inside the chamber to ensure a good homogeneity of the hygro-thermal conditions (Fig. $2 \& 3$ ).

Stability of temperature and relative humidity in the climatic chamber-Calibration of the relative humidity measurements

Wood needs time to attain its equilibrium. This requires stable conditions in the chamber over very long periods of time. The hygro-thermal conditions are controlled by the measurement of two temperature values (dry temperature of air and temperature of water). Indeed, Platinum sensors (Pt 100) are very accurate (typically $0.1^{\circ} \mathrm{C}$ ) and present almost no drift. In addition, the actual conditions are also measured independently using a more accurate temperature sensor (Pt 1000) and a relative humidity (capacitor) sensor (Honeywell IH-3602C) placed near the samples. The accuracy of this sensor has been calibrated with a dew point analyser placed inside the 'sample box'. In the range $0-75 \%$ of relative humidity, the quality of the correlation between both apparatuses $\left(r^{2}=0.999\right)$ allows the measured values to be corrected with a high precision.

The stability of the air temperature and humidity was tested over several weeks. All sensors are connected to a data acquisition device (HP 34970A) controlled by a program developed in the laboratory. Figure 4 depicts a test in which two periods can be observed. In the first one, the dry bulb temperature of the air is set at $23.9^{\circ} \mathrm{C}$ and the water temperature at $10.1^{\circ} \mathrm{C}$. During 10 days, the temperature is stabilised at $23.9^{\circ} \mathrm{C}$ with a deviation of $\pm 0.03^{\circ} \mathrm{C}$. The relative humidity in the chamber is $42 \% \pm 1 \%$. In the second period, the temperature is equal to $26.9^{\circ} \mathrm{C} \pm 0.05^{\circ} \mathrm{C}$ and the relative humidity to $77 \% \pm 1.5 \%$.

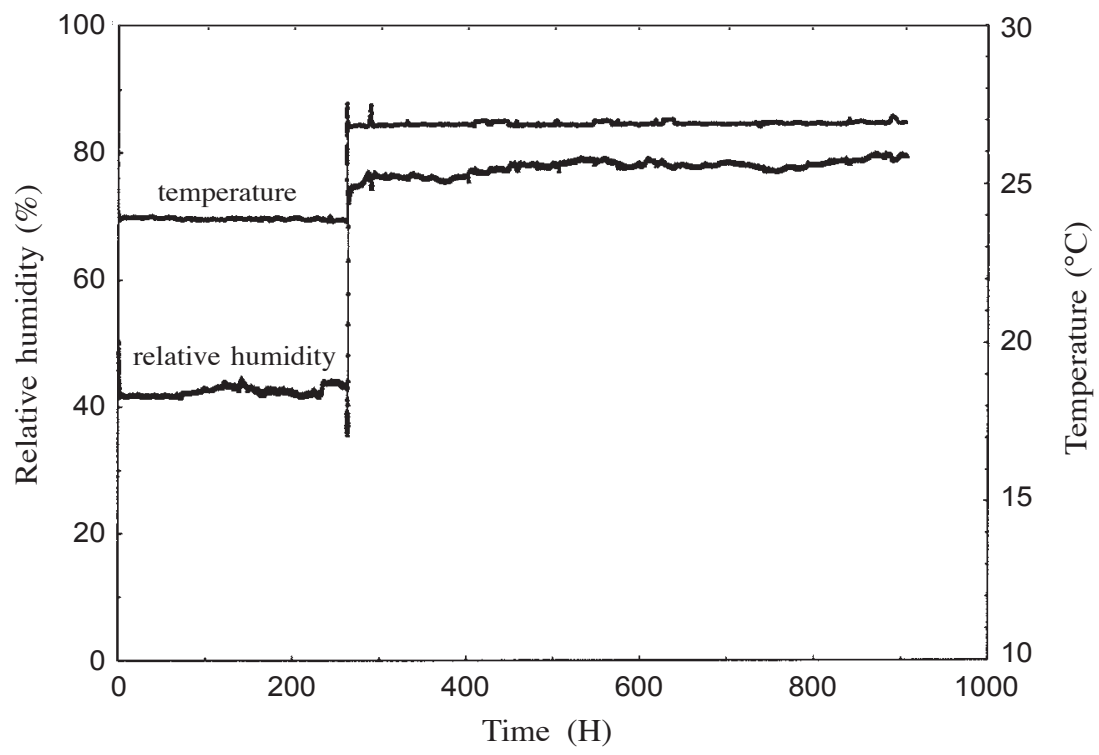

Fig. 4. Stability of the air-conditions in the climatic chamber over 39 days. 


\section{Shrinkage experiments}

Sampling

In our deterministic approach, it is granted that the variability of oak shrinkage can be explained by the anatomical pattern. The sampling has been chosen with a lot of care. A great variety of anatomical patterns were selected for this purpose. The main objective is to obtain a sampling that is representative of the large diversity of structures that are present in oak from France. The laboratory has a great database of oak samples in radial strip form. For each one, numerous parameters have been collected (Bakour 2003) and in particular:

A. For each radial strip (from the pith to the bark):

- species: sessile oak (Quercus petraea Liebl.) or pedunculate oak (Quercus robur L.)

- forest of origin

- position of the strip in the trunk (height, etc.)

B. For each annual ring of the strip:

- age (calendar age: measured from the bark)

- distance to the bark

- average density (measured by X-ray densitometry)

- annual ring width

This huge database of 37,000 annual rings and their characteristics allowed us to select samples having a similar age and the same annual ring width but different density values or, on the contrary, samples having the same density but different annual ring width values. This sampling permits separation of the effect of age, annual ring width or density and to focus on the effect of the anatomical structure. Twelve samples have been selected according to these criteria. This sampling is representative of the large diversity of the annual ring patterns that are present in France. For each a representative steady growing zone that includes three annual rings in the radial direction were selected (Fig. 5). The tangential dimension was chosen to include 3 or 4 large rays. A cross section (700 $\mu \mathrm{m}$ thick) of each sample was cut (Fig. 6) using a dual micro-circular saw (Struers (C) Accutom 5). The precision of this apparatus ensures a very regular thickness and an excellent surface quality.

\section{Calculation of strain field from image correlation}

The strain field due to shrinkage is determined by comparison of two X-ray images of the same sample observed at different moisture content values. The detailed algorithm is described in Badel \& Perré (2001). Assuming that image 1 is the reference image and has to be compared to image 2, the principle is as follows. A 2-D strain field is applied to 'image 1' and the new position of each pixel is calculated. For this process, the strain field is assumed to be constant over the entire image. This allows the grey level of a new virtual image to be interpolated. This 'virtual' image is compared to the real deformed image by the following objective function:

$$
\text { Diff }=\frac{\sum_{\text {image }}^{i, j} \begin{array}{c}
\text { virtual } \\
G_{i, j}-G_{i, j}
\end{array}}{N}
$$




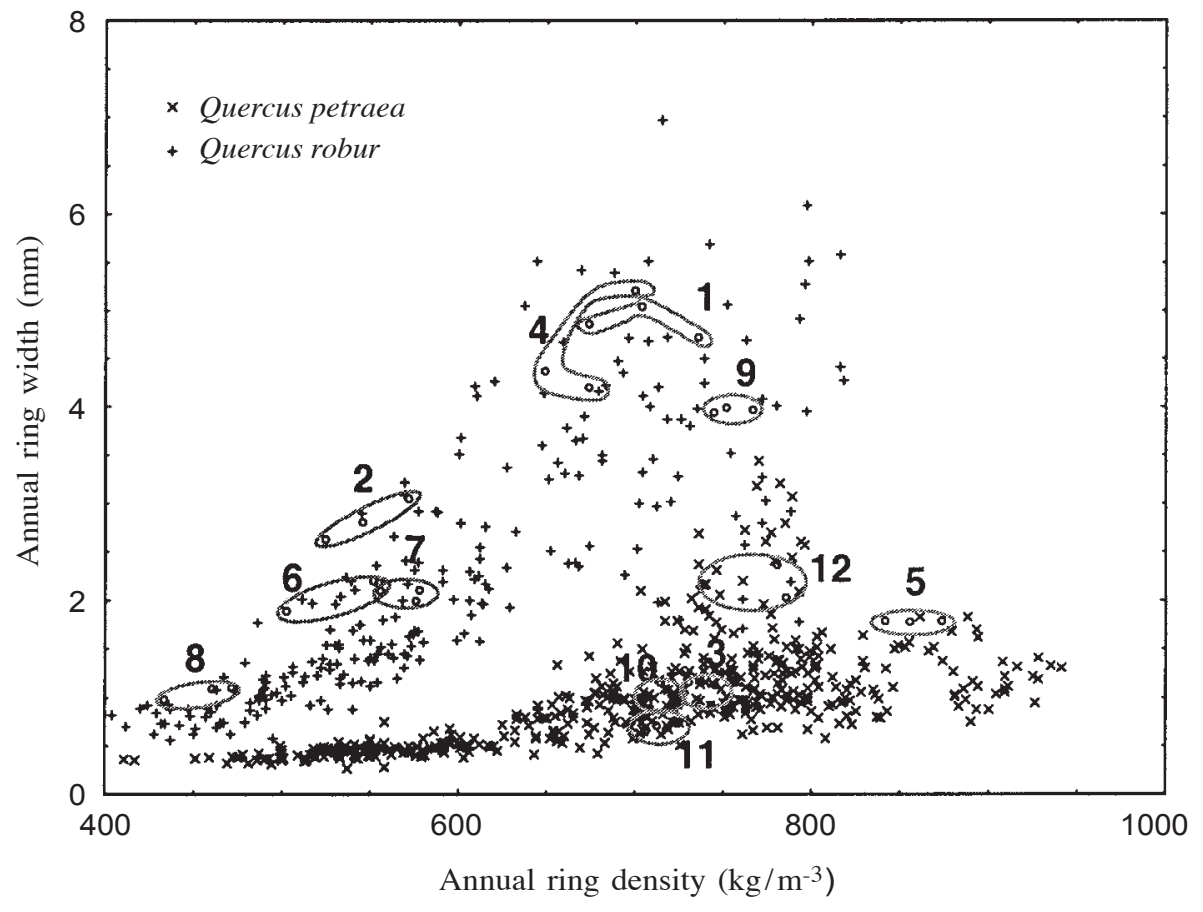

Fig. 5. Annual ring width and density for twelve trees (all the annual rings). One sample, which includes three consecutive annual rings (black circles), has been selected in each tree. They represent a large range of values.

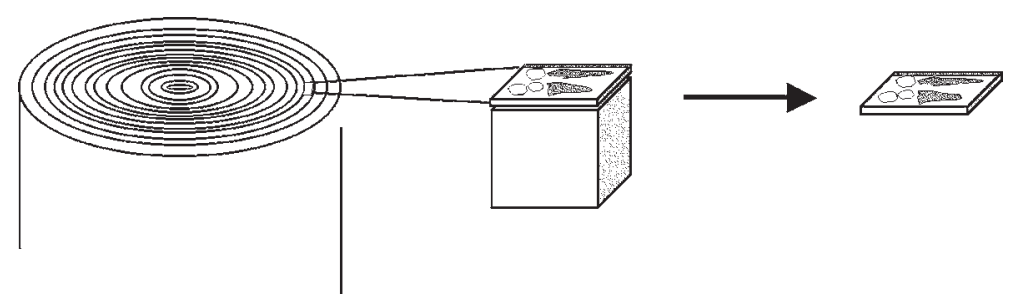

Fig. 6. Sampling protocol. A thin slice is cut in the transverse plane for each region of interest. The sample is composed of 3-4 annuals rings in the radial direction and 3-4 large ray cells along the tangential direction.

where $G_{\text {virtual }}\left(G_{\text {deformed }}\right)$ is the grey level of pixel in the calculated image (respectively in the experimental deformed image $)$ and $N$ the total number of pixels $(1317 \times 1035$ pixels). The strain field is determined by minimising this objective function using an inverse method (Fig. 7).

To remain valid in the case of large displacements, six degrees of freedom are estimated in this procedure: three for the solid displacement (translation + rotation) and three for the two-dimensional strain field tensor. When the sample is cut along the material 


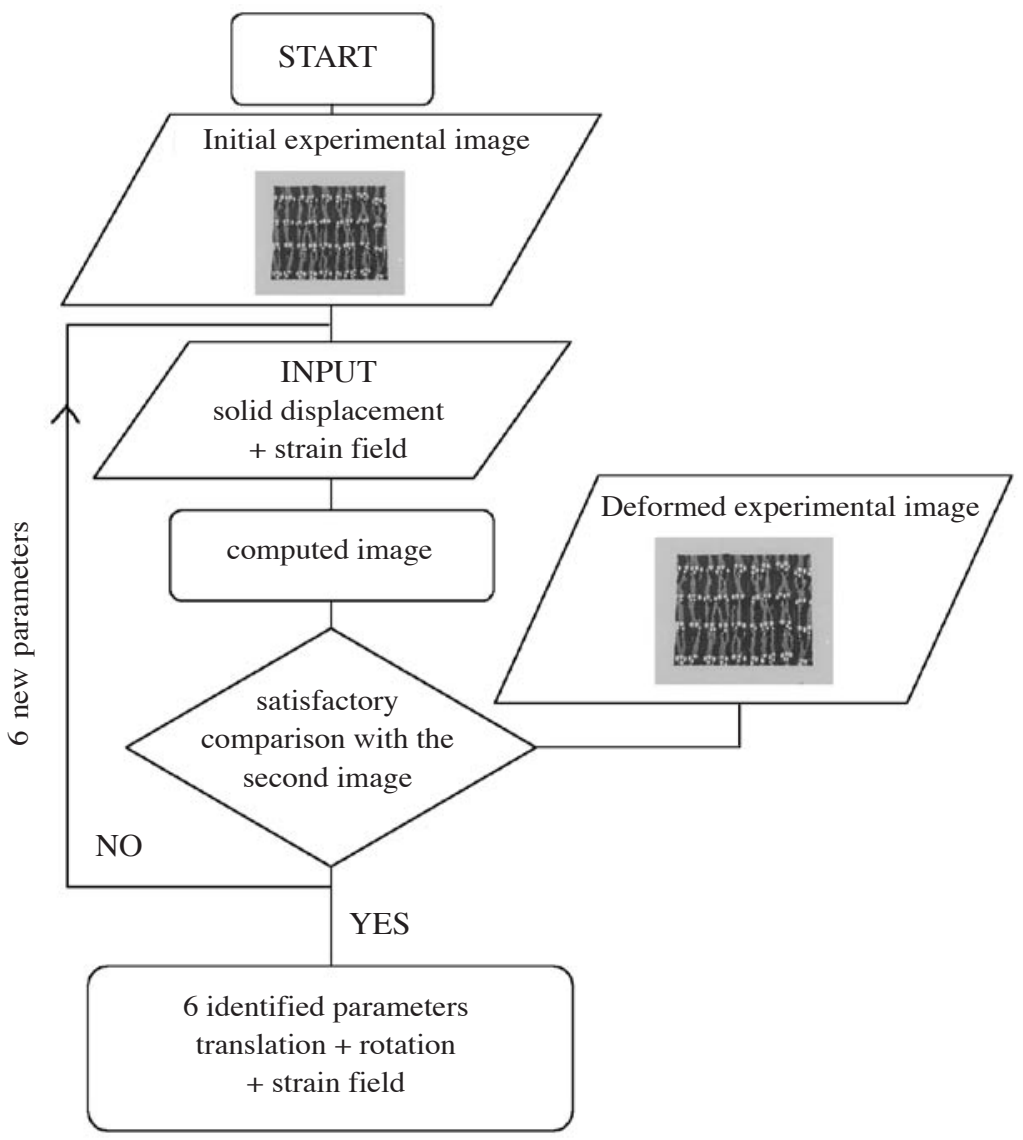

Fig. 7. The 2D strain field determination process. A strain field is applied to the initial image until the resulting image fits the experimental deformed image. Clearest areas (around the sample or in the big vessels) correspond to zones without attenuation of the incident beam.

directions, the diagonal terms of the strain field tensor give the radial and tangential shrinkage values while the shear deformation should be close to zero. This leads to average shrinkage values for each direction of the wood sample.

\section{Relative humidity-strain curves and shrinkage coefficients}

When the experiment starts, the samples are close to their equilibrium at room conditions. During a first step, the relative humidity is set at around 55\% and the temperature at $24^{\circ} \mathrm{C}$. After several days of stabilisation, each sample is placed under the X-ray beam using to the motorised rotating sample holder and an image is recorded. Then we proceed to additional steps, each corresponding to a new value of the relative humidity. The samples are conditioned with a relative humidity equal to $75 \%$. Then the air is dried down to $18 \%$. Therefore, the complete cycle is as follow: $55-75-50-28-18 \%$. 


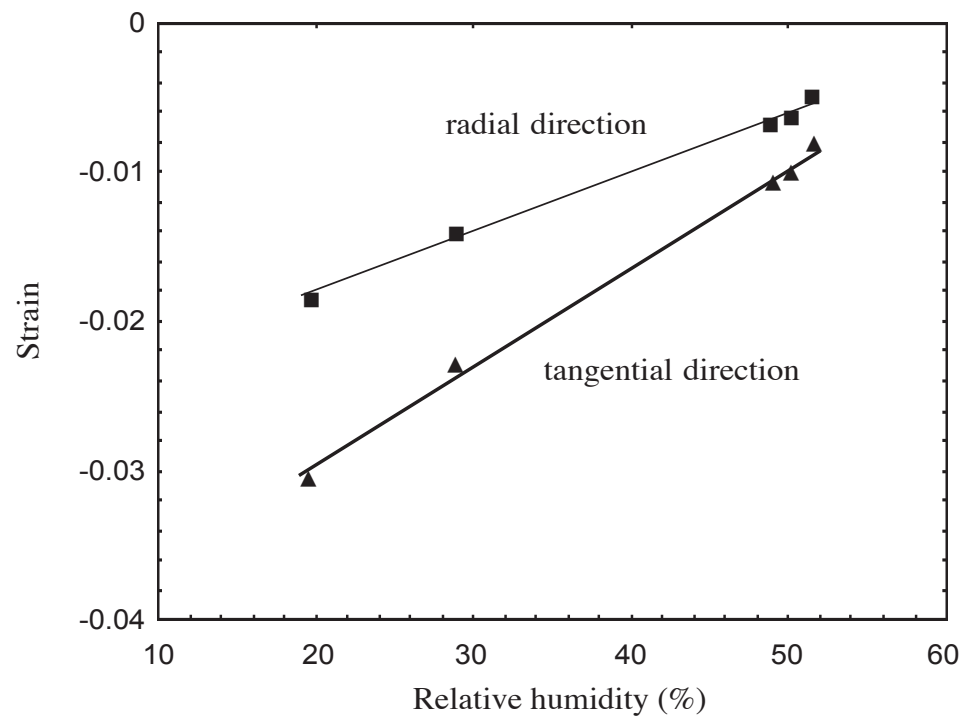

Fig. 8. Swelling curves in radial and tangential directions. The strain is calculated according to the size at the highest humidity level, the temperature is around $24^{\circ} \mathrm{C}$. The slope of the curve indicates a swelling coefficient $(\% / \%)$.

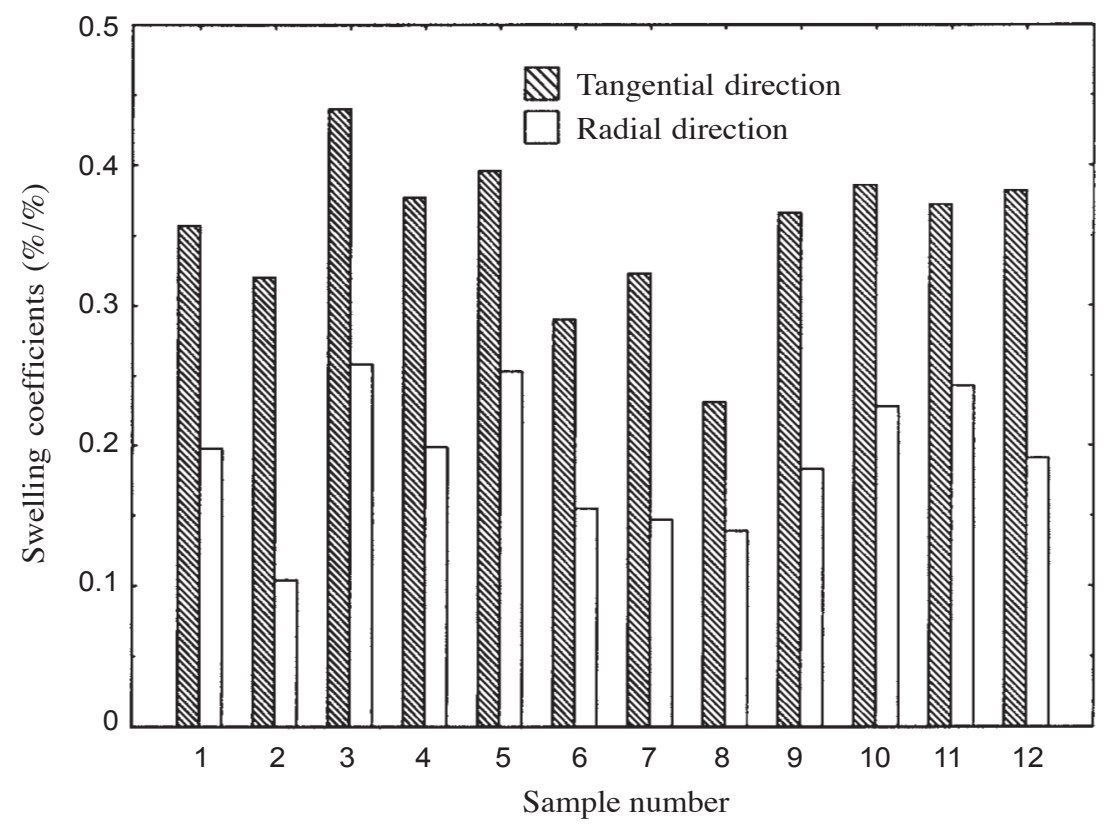

Fig. 9. Swelling results for the twelve samples. The swelling coefficients are extracted from the previous swelling curves $(\% / \%)$. 
Typically, the observed results for the strain due to moisture content variation are commonly $-1.5 \%$ in the radial direction and $-3 \%$ in the tangential direction. On the image this corresponds to changes of more or less 10 and 20 pixels respectively in radial and tangential directions.

For each sample, the image obtained for the highest humidity $(\mathrm{RH}=75 \%)$ is chosen as reference for the strain field measurement. All shrinkage values are defined as the change in size from this reference. For each sample, the deformation is plotted versus the relative humidity of the air. The slope of these curves (Fig. 8) defines the shrinkage coefficients in radial and tangential directions. Finally, the swelling coefficient is calculated in percent deformation per percent humidity variation.

\section{RESULTS AND DISCUSSION}

Twelve samples were carefully selected to ensure a wide range of variation in both the density and the annual growth ring. For this study to be relevant, one has to remember that, because each sample contains more than one annual ring, steady growing zones were selected in each tree. Thus, the average values over the sample are representative of the values (ring width and density) of each annual ring embedded in the sample. Thanks to the sample holder, the twelve samples were characterised simultaneously; hence they were exposed to the same environment. This point is important because the experiment lasted several weeks. From the results (Fig. 9), one can notice two observations:

- the great variability of the shrinkage values between samples,

- the difference between radial and tangential direction, the average tangential swelling being 1.84 times higher than the radial one. However, this average value should not hide the great variability of the anisotropy ratio.

However, it is not so easy to go further in the interpretation of these results, namely to draw some relations between the swelling coefficients and the annual ring structure (Fig. 10). As first attempt, macroscopic parameters like annual ring width and/or its age can be involved (Table 1).

Surprisingly, the statistical models found in the literature for oak do not consider the sample density as input parameter. Probably, for large samplings of oak, density is closely tied to the age and the ring width. A first model proposes to predict shrinkage using only these two parameters, age and ring width (Eyono Owoundi 1992) (model 1). A second model is more complex and includes, in addition, the position in the trunk (height and distance from the pith) (Le Moguedec 2000) (model 2). The latest is only available for Quercus petraea.

We applied these models to our sampling using all the parameters that are required. Figure 11 depicts the comparison between the experimental results and the two statistical predictions. In the case of radial direction, the overall results show that both models underestimate the swelling properties. The most interesting observation is that the range of predicted values is much smaller than the wide range of experimental data. These statistical models are sensitive to age of the annual ring. Because of the similar 
Table 1. Synoptic table of macroscopic characteristics and experimental swelling results.

\begin{tabular}{|c|c|c|c|c|c|c|}
\hline 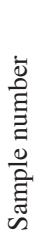 & 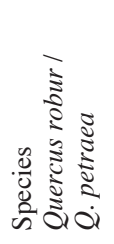 & 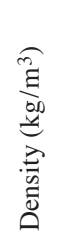 & 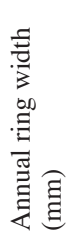 & 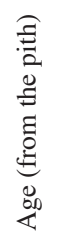 & 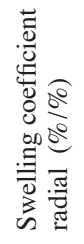 & 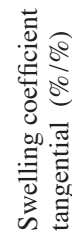 \\
\hline 1 & $\mathrm{R}$ & 674 & 4.91 & 98 & 0.198 & 0.357 \\
\hline 2 & $\mathrm{R}$ & 572 & 3.05 & 107 & 0.104 & 0.320 \\
\hline 3 & $\mathrm{P}$ & 746 & 1.13 & 118 & 0.258 & 0.440 \\
\hline 4 & $\mathrm{R}$ & 649 & 4.38 & 96 & 0.199 & 0.377 \\
\hline 5 & $\mathrm{P}$ & 874 & 1.8 & 128 & 0.253 & 0.396 \\
\hline 6 & $\mathrm{R}$ & 556 & 2.09 & 114 & 0.155 & 0.290 \\
\hline 7 & $\mathrm{R}$ & 555 & 2.21 & 91 & 0.147 & 0.323 \\
\hline 8 & $\mathrm{R}$ & 461 & 1.11 & 118 & 0.139 & 0.231 \\
\hline 9 & $\mathrm{R}$ & 768 & 4.01 & 127 & 0.183 & 0.366 \\
\hline 10 & $\mathrm{P}$ & 708 & 0.94 & 98 & 0.228 & 0.386 \\
\hline 11 & $\mathrm{P}$ & 723 & 0.77 & 99 & 0.243 & 0.372 \\
\hline 12 & P & 786 & 2.06 & 110 & 0.191 & 0.382 \\
\hline
\end{tabular}

age of our annual rings (around one hundred years), our sampling can explain the poor variation that can be explained by this parameter (Table 1). However, one should note that this narrow range of variation was obtained in spite of the very large range of the annual ring width (from 0.77 to $4.91 \mathrm{~mm}$ ). It is obvious that the predicted values were far from the extreme values observed. The gap between predicted and experimental values can be quantified for each sample as follows:

$$
\operatorname{error}(\%)=\frac{\mid \text { experimental }- \text { predicted } \mid}{\text { experimental }} \times 100
$$

The average error for the twelve samples is, respectively, $31.6 \%$ for the first model and $31 \%$ for the second one.

The same observations can be established in the case of the tangential direction but the underestimation is less drastic. Because the average swelling coefficients, experimental and predicted, are closer in this case, the overall difference is noticeably smaller (13.8\% for both models). Though, this better average agreement does not hide the great discrepancy when the experimental swelling coefficient is low or high.

Certainly these statistical approaches give tendencies that could be available for a large sampling but they are not accurate and they cannot be applied individually to one single sample to predict its physical properties. Indeed the swelling-annual ring width relationship has only a statistical meaning. In our sampling some samples obey this rule. This is the case for sample 8, which depicts a thin annual ring and low swelling values. This is true also for samples 1, 4 and 9, having large annual rings and high swelling values. These samples - let us call them 'typical' samples - obey the well-known rule 
of oak growth: the proportion of latewood usually increases with the annual ring width. Because latewood usually contains fibre zones, a dense tissue, the swelling coefficient is large for a large ring widths in these typical samples.

But oak is complex and cannot be embedded in simple statistical relations, which discard the great anatomical variability of this species. So, it is not surprising to find 'atypical' samples. Samples 2 and 6, for example, exhibit lower swelling properties than samples 3,10 or 11 , both in radial and tangential direction, in spite of their larger

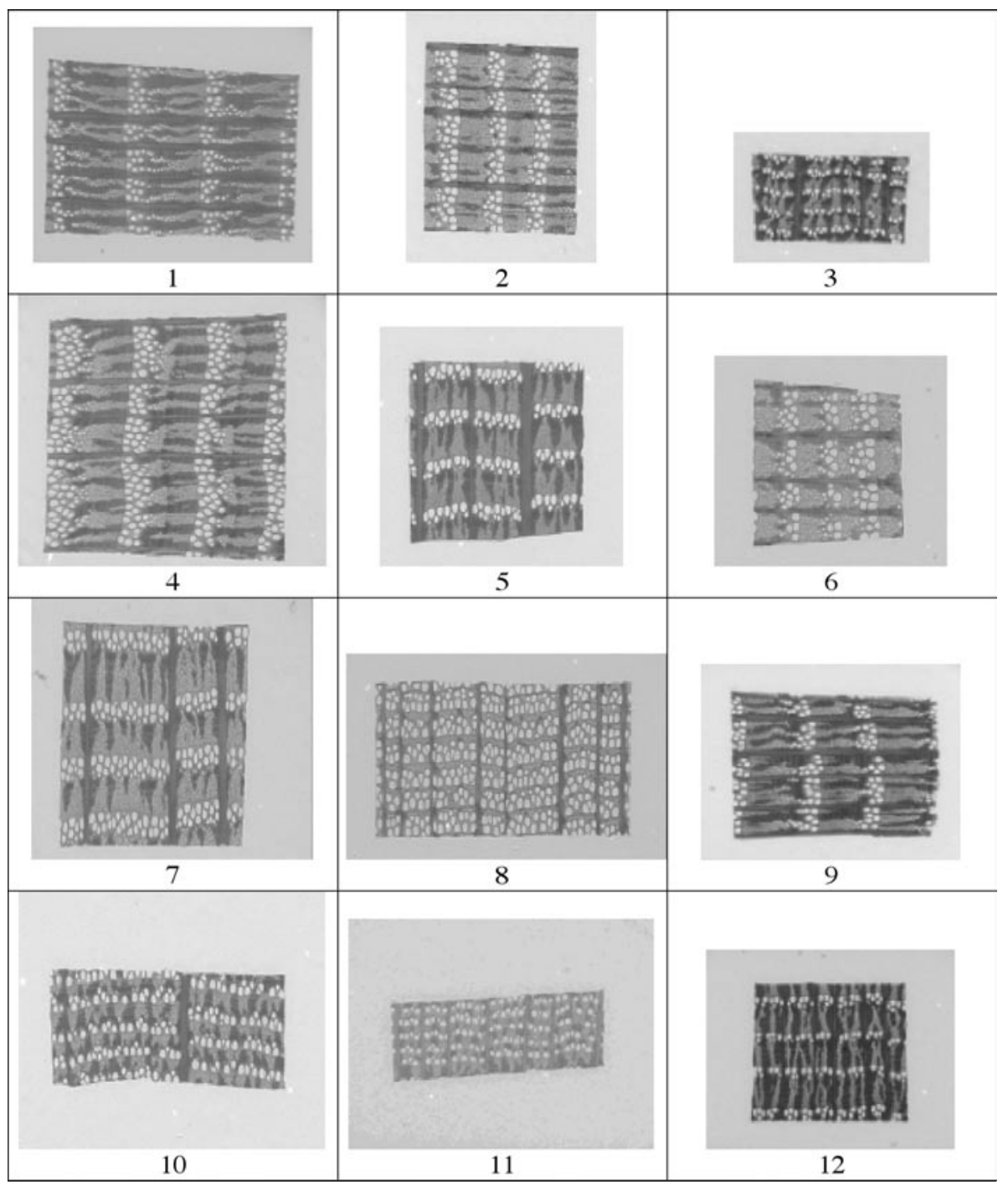

Fig. 10. X-ray images of the twelve samples. The grey levels range from 0 (darkest parts correspond to a high $\mathrm{X}$-ray attenuation; i.e. high density) to 1 (no attenuation ; density $=0$ ). 


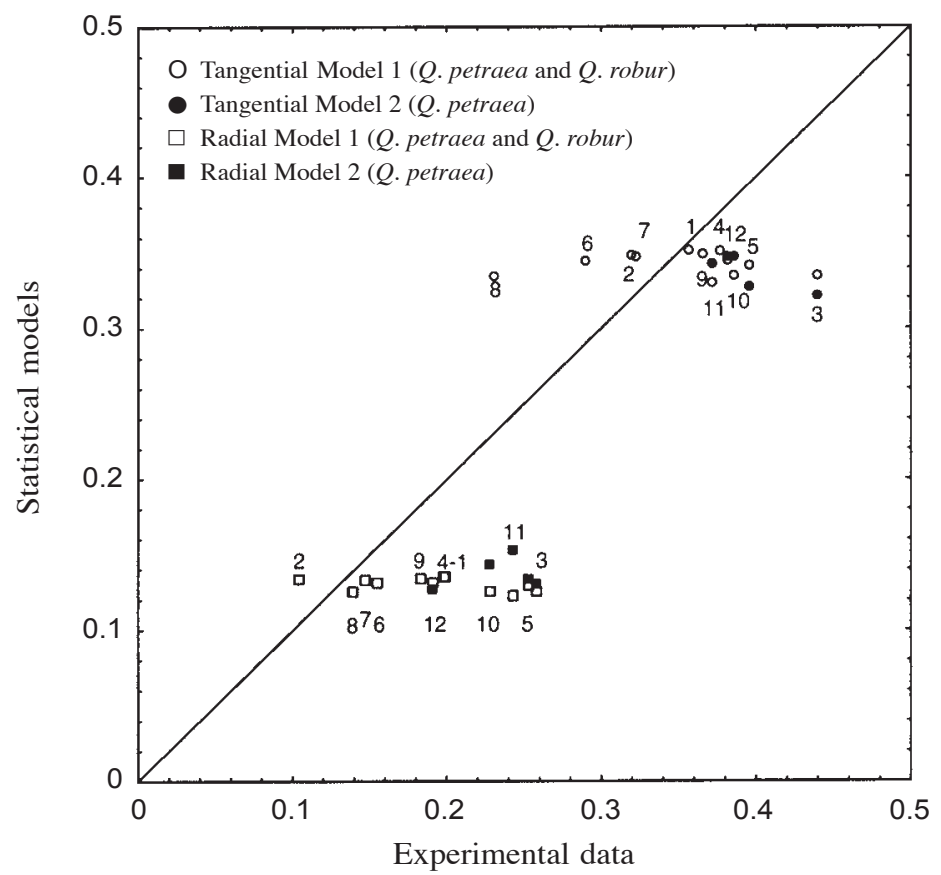

Fig. 11. Comparison between experimental results and two existing statistical models.

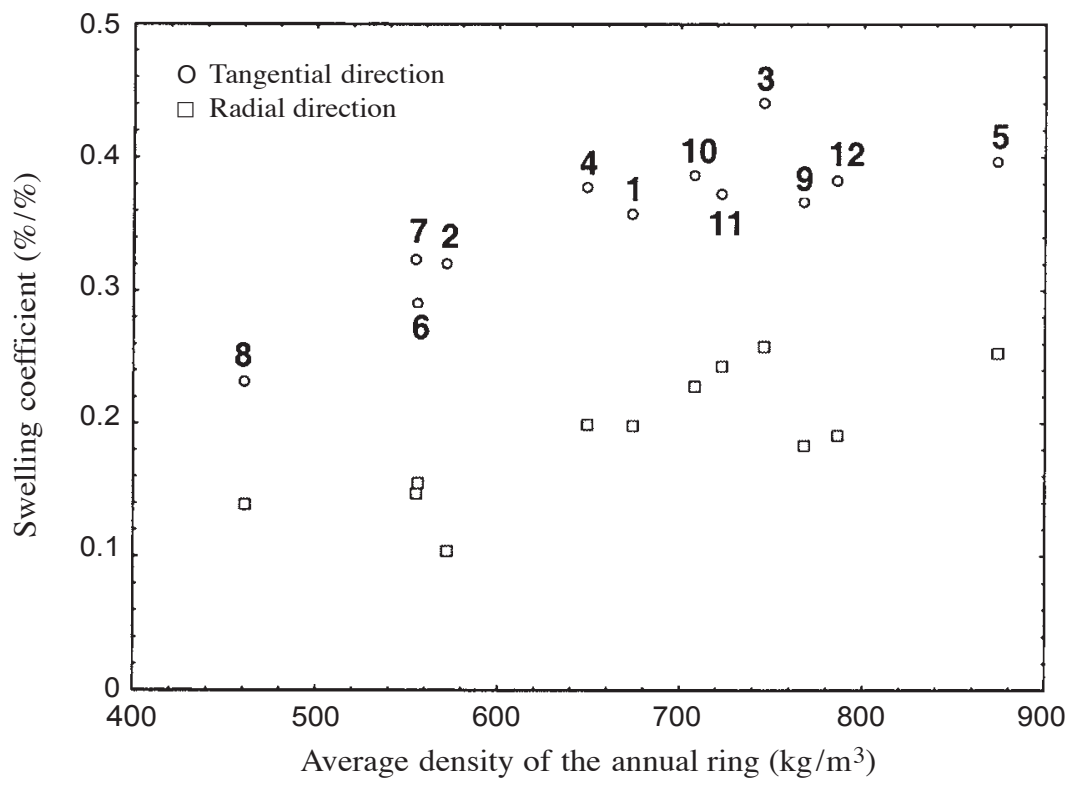

Fig. 12. The swelling behaviour increase according to the density. A great variability remains around the overall tendency. 
annual ring width. The observation of the anatomical structure reveals that the proportion of fibre zone is poor for samples 2 and 6 regarding their large value of ring width.

From the previous comments it seems that all samples obey one simple and wellknown rule: the swelling value is positively related to the density. However, even if a general trend is exhibited, the swelling-density relationship presents an important level of scatter (Fig. 12). Again, a better explanation is needed why samples having a similar density present different swelling values (samples 3 and 12 for example) or why samples with a different density have similar swelling values (samples 4 and 9 for example).

In order to answer all these questions, a deterministic approach is in progress in our research team. As a first step, our approach assumes that the proportion and shape of the tissue at the annual ring scale can explain the major part of the swelling properties (Perré \& Badel 2003). However, one has to keep in mind that, at the microscopic level, tissues can also show a certain level of variability. The first parameter that can be used to check this is the local density of each tissue (Guilley 2000). Thanks to the quality of our digital X-ray imaging system, we succeeded in determining the local density from the sample images. Figure 13 shows the comparison of the local density values of the fibre zone and the parenchyma zone for each sample. It seems that the variation of tissue density between samples is not so important. The overall results are comparable except for one atypical sample (sample 5). This sample has a higher density than the others for both fibre and parenchyma zones. This observation could explain why this sample is much denser than the others (Fig. 12), but has swelling values comparable to the whole set of samples (Fig. 11).

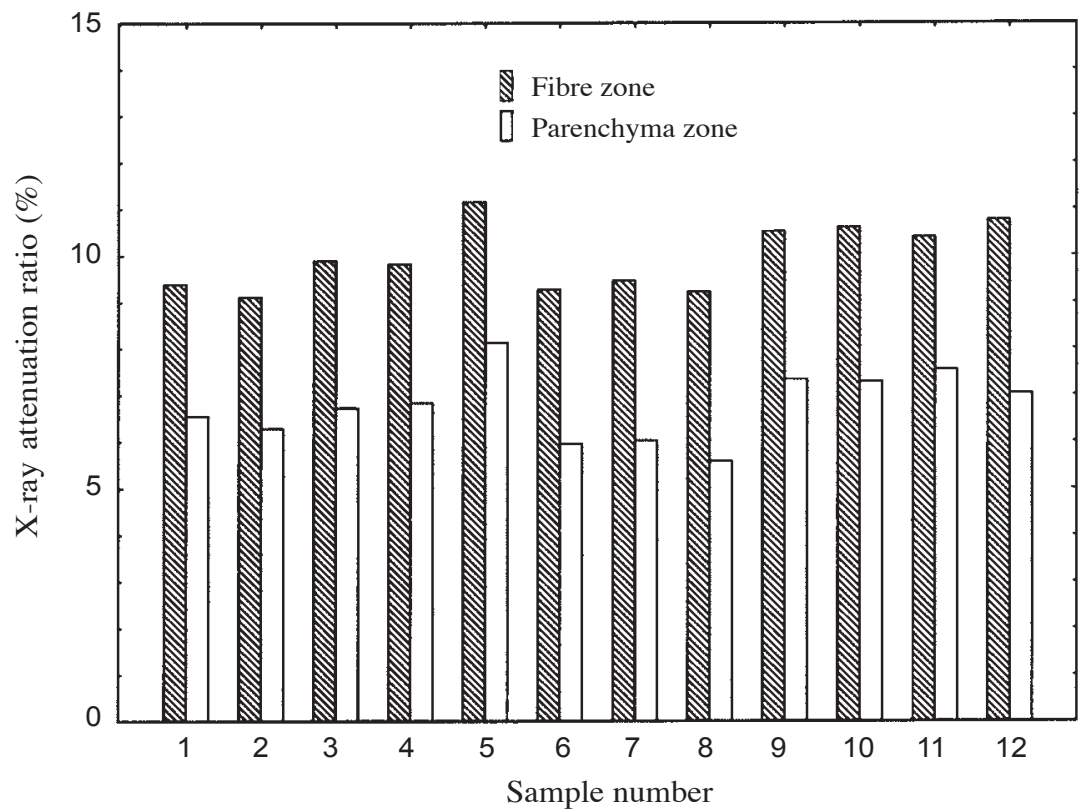

Fig. 13. X-ray attenuation ratio of fibre zone and parenchyma zone. This ratio is physically directly linked to the local density. 


\section{CONCLUSION}

We presented the new possibilities that can be offered by the coupling of an X-ray device and an air conditioner. This device is able to collect simultaneously complementary information on cross sections of wood:

- the morphology of different tissues at the level of the anatomical pattern,

- simultaneously the swelling coefficients in radial and tangential directions,

- information about the local density of tissues.

By controlling the conditioning of the relative humidity and temperature of the air, this experimental device insures stable conditions of a whole set of samples during several weeks, the time required to stabilise their moisture content. The geometry of the sample is defined by a huge number of pixels and provides a very good relative accuracy for dimensional changes in both radial and tangential directions. By using X-rays, this dimensional measurement is performed in situ without contact and without perturbation of the air conditions.

A set of oak samples has been carefully selected from a huge collection to ensure wide variation in both density and ring width. The comparison of the experimental results with existing predictive models shows that the macroscopic parameters like annual ring width and/or its age and/or its position in the tree allow only very poor dimensional change predictions to be obtained.

At the annual ring level, oak wood is clearly a composite material and the number, shape and detailed spatial organisation of the different zones have to be taken into account to explain the variability of its properties. This implies a comprehensive approach based on multiscale methods and is the object of a forthcoming study.

\section{ACKNOWLEDGEMENTS}

The authors would like to acknowledge the "Région Lorraine" for funding one part of this work.

\section{REFERENCES}

Badel, E. \& P. Perré. 1999. Détermination des propriétés élastiques d'éléments individuels du plan ligneux du chêne par des essais de traction sur micro-éprouvettes. Ann. For. Sci. 56: 467-478.

Badel, E. \& P. Perré. 2001. Using a digital X-ray imaging device to measure the swelling coefficients of a group of wood cells. NDT \& E 34: 345-353.

Badel, E. \& P. Perré. 2002. Predicting oak wood properties using X-ray inspection: representation, homogenisation and localisation. Part I: Digital X-ray imaging and representation by finite elements. Ann. For. Sci. 59: 767-776.

Bakour, R. 2003. Influence de l'espèce et de la provenance des deux principaux chênes français (Quercus robur L.; Quercus petraea Liebl.) sur la structure anatomique et les propriétés du bois de merrain. ENGREF, Nancy.

Botosso, P.C. 1997. Une méthode de mesure du retrait microscopique du bois. ENGREF, Nancy.

Boutelje, J.B. 1962. On shrinkage and change in microscopic void volume during drying, as calculated from measurements on microtome cross sections of Swedish pine. Svensk Papperstidning ??: 209-215. 
El Amri, F. 1987. Contribution à la modélisation élastique anisotrope du matériau bois-feuillus et résineux. I.N.P.L., Nancy.

Evans, R. \& J. Ilic. 2001. Rapid prediction of wood stiffness from microfibril ample and density. For. Prod. J. 51: 53-57.

Eyono Owoundi, R. 1992. Modélisation de la rétractibilité du bois en relation avec des paramètres de la structure de l'accroissement annuel et de la position dans l'arbre chez Quercus robur et Q. petraea. ENGREF, Nancy.

Farruggia, F. \& P. Perré. 2000. Microscopic tensile test in transverse plane of earlywood and latewood parts of spruce. Wood Sci. Technol. 34: 65-82.

Guilley, E. 2000. La densité du bois de chêne sessile (Quercus petraea Liebl.): Elaboration d'un modèle pour l'analyse des variabilités intra et inter arbre; origine et évaluation non destructive de l'effet "arbre"; interprétation anatomique du modèle proposé. ENGREF, Nancy.

Harris, J.M. \& B.A. Meylan. 1965. The influence of microfibril angle on longitudinal and tangential shrinkage in Pinus radiata. Holzforschung 19: 144-153.

Kawamura, Y. 1979. Studies on the properties of rays I. Mokuzai Gakkaishi 25: 455-460.

Le Moguedec, G. 2000. Modélisation de propriétés de base du bois et de leur variabilité chez le chêne sessile (Quercus petraea Liebl.). Simulation en vue de l'évaluation d'une ressource forestière. ENGREF, Nancy.

Lichtenegger, H., A. Reiterer, S. Tschegg \& P. Fratzl. 1999. Variation of cellulose microfibril angles in softwoods and hardwoods - a possible strategy of mechanical optimization. J. Struct. Biol. 128: 257-269.

Mariaux, A. 1989. La section transversale de fibre observée avant et après séchage sur bois massif. Bois et Forêts des Tropiques 221: 65-76.

May, B.K. \& P. Perré. 2002. The importance of considering exchange surface area reduction to exhibit a constant drying flux period in foodstuffs. J. Food Engin. 54: 271-282.

Perré, P. 2002. Wood as a multi-scale porous medium: observation, experiment, and modelling. First Intern. Conf. European Soc. for Wood Mechanics (selected and reviewed papers), EPFL, Lausanne, Switzerland.

Perré, P. \& E. Badel. 2003. Predicting oak wood properties using X-ray inspection: representation, homogenisation and localisation. II. Computation of macroscopic properties and microscopic stress fields. Ann. For. Sci. 60: 247-257.

Persson, K. 2000. Micromechanical modelling of wood and fiber properties. Lund University, Lund, Sweden.

Rondot, S., J. Cazaux, O. Aaboubi, J.P. Chopart \& A. Olivier. 1994. Following ion diffusion in solution. Science 263: 1739-1741.

Yamamoto, H., F. Sassus, M. Ninomiya \& J. Gril. 2001. A model of anisotropic swelling and shrinking process of wood. 2. A simulation of shrinking wood. Wood Sci. Technol. 35: $167-181$. 